\title{
Importance of Supporting School Education on Radiation After the Fukushima Daiichi Nuclear Power Plant Accident
}

\author{
Shimizu $\mathrm{Y}^{*}$, lida $\mathrm{H}$, Nenoi $\mathrm{M}$ and Akashi M
}

National Institute of Radiological Sciences, National Institutes for Quantum and Radiological Science and Technology, 4-9-1 Anagawa, Inage-ku, Chiba 263-8555, Japan

\begin{abstract}
The National Institute of Radiological Sciences (NIRS) in Japan has conducted training courses for professionals to obtain correct knowledge on radiation and its use in various fields. After the Fukushima accident, the demands for education on radiation not only by professionals but also by students increased. NIRS started school visits to conduct classes on radiation basics to ninth-grade (14/15-year-old) students in public junior high schools in cooperation with the Chiba city education board. After the classes, a questionnaire survey was conducted to evaluate the school visits and to improve the contents of the education. Almost half of the students thought that the contents of the lecture were slightly difficult or difficult to understand. Use of devices or instruments such as a cloud chamber, TV phone, or survey meter was helpful to arouse the students' interest. The school visits significantly changed the students' feelings toward radiation from "fear" to "interest". Our preliminary trial to conduct a class on radiation basics in junior high school suggests that detection of radiation by students and its visualization are very helpful in educating school children on radiation.
\end{abstract}

Keywords: Radiation education; School visits; Students; Japan

\section{Introduction}

Radiation exposure is a unique event because it cannot be detected by the human senses. Nevertheless, we are of course always being exposed to natural radiation. Today, moreover, radiation is used not only in medicine but also in science, industry, and for the generation of electricity. Ionizing radiation is useful for mankind and, in fact, is now essential for human life: for example, for roentgenographic examinations, nondestructive inspections, sterilization of medical instruments, and so on. However, radiation had not been taught in schools for 30 years until the Japanese school curriculum guidelines were revised in 2008 [1].

A huge earthquake struck the Pacific coast of eastern Japan at 14:46 on March 11, 2011 and triggered a tremendous tsunami. This earthquake and tsunami caused serious damage to the Fukushima Daiichi Nuclear Power Plant (NPP) operated by Tokyo Electric Power Co. (TEPCO). This damage resulted in large amounts of radioactive material being released into the environment. After this accident, many misunderstandings concerning radiation and its effects were spread in the general public, and even 6 years after the accident, there are still reports by mass media of misunderstandings about radiation that have led to discrimination in schools $[2,3]$. Thus, education on radiation and its effects is necessary in today's society.

Sinceits establishment in 1959, the Human Resources Development Center (HRDC) of the National Institute of Radiological Sciences (NIRS) under the National Institutes for Quantum and Radiological Science and Technology has conducted various training courses on the basics of radiation, radiation protection, radiation emergency medicine, and other topics mainly for professionals. In Japan, however, no systematic education on radiation basics was conducted in elementary or junior high schools. Although local governments with nuclear facilities such as NPPs ran a training/education system on radiation and its effects before the accident, this system was limited to 19 prefectures and focused on first responders and health care providers. In this article, we clarify and discuss problems raised in society after the accident and introduce our trial and efforts to educate students on the basics of radiation.

\section{Materials and Methods}

A questionnaire was prepared for the students $(n=258)$ who took the class on radiation basics that NIRS conducted at school visits. The students were ninth-graders (14/15 years old) from 8 classes in Chiba city junior high schools.

The questionnaire consisted of the following closed questions: What is your most favorite subject?; What is your least favorite subject?; How was the special lesson?; Which subject was most interesting? (Multiple answers were allowed for this question.); Before you took the special lesson, how had you felt about radiation?; After you took the special lesson, how do you feel about radiation?; and Is the knowledge on radiation useful for your life?

\section{Results}

\section{Training courses at NIRS}

We have conducted both regularly scheduled and on-demand courses even before 2011. After the Fukushima accident, the number of training courses held at NIRS increased dramatically; the number of regularly scheduled or Fukushima-related courses increased to more than 30 in 2014 [4,5] (Figure 1A). These courses included those for first responders or communicators in local governments. Meanwhile, it is noteworthy that on-demand training courses have also increased: almost 20 courses were conducted in 2016. Figure 1B shows the on-demand courses according to the target population. Half of these courses were for students from elementary school to university level, and they were held at the request of the schools or local education boards.

*Corresponding authors: Yuko Shimizu, National Institute of Radiological Sciences, National Institutes for Quantum and Radiological Science and Technology, Japan, Tel: +81433826204; Fax: +81432517819; E-mail: shimizu.yuko@qst.go.jp

Received February 08, 2017; Accepted March 23, 2017; Published March 27, 2017

Citation: Shimizu Y, lida H, Nenoi M, Akashi M (2017) Importance of Supporting School Education on Radiation After the Fukushima Daiichi Nuclear Power Plant Accident. J Health Educ Res Dev 5: 214. doi: 10.4172/2380-5439.1000214

Copyright: (๑) 2017 Shimizu Y, et al. This is an open-access article distributed under the terms of the Creative Commons Attribution License, which permits unrestricted use, distribution, and reproduction in any medium, provided the original author and source are credited. 
A

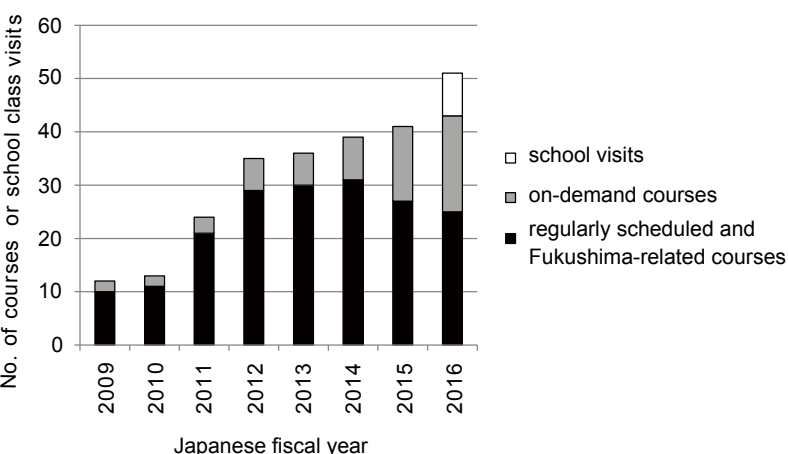

B

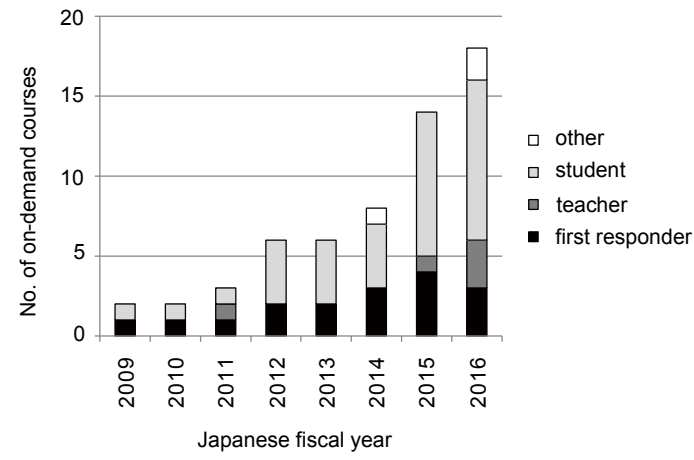

Figure 1: Changes in the number of training courses held in the HRDC of NIRS. (A) Changes in the number of three subgroups of training courses held in the HRDC. Courses are classified as school visits, on-demand training courses, and regularly scheduled and Fukushima-related courses. Data are presented for the Japanese fiscal year, which is from April to March of the following year. (B) Changes in the number of on-demand training courses as classified by trainees. Data are presented for the Japanese fiscal year.

\section{Trial of systematic school visits for radiation education}

NIRS started to visit schools from 2016 to support education on radiation basics in cooperation with the Chiba city education board and to improve the contents of radiation education. NIRS staff visited two schools in 2016, and 258 students took the class. A 45-minute-class on radiation basics was taken by almost all of the ninth-grade students at two public junior high schools in Chiba city. Each class consisted of less than 40 students so that we could devote our attention to all of the students, and NIRS conducted 8 classes in total. The class covered the characteristics of radiation, natural radiation in the environment, its effects on humans, and its application in medicine and industry. These contents have been included in the school curriculum guidelines. To make sure the students understood well, NIRS explained radiation in plain words and phrases without using scientific or technical words. To arouse the students' interest, a cloud chamber was used. Although radiation cannot be detected directly by using our senses, it can be detected indirectly. A cloud chamber is a detector that allows visualization of the tracks of charged particles. We used a large-scale cloud chamber (Toda-type desk cloud chamber B-112, RADO) to show the tracks of the radiation and radioactive decay (Figures 2A-2C). Moreover, using a survey meter, the students could detect natural radiation in mineral deposits under the supervision of experts. In addition, a live experiment in a radiation-controlled area at NIRS was shown to students via a TV phone.
A

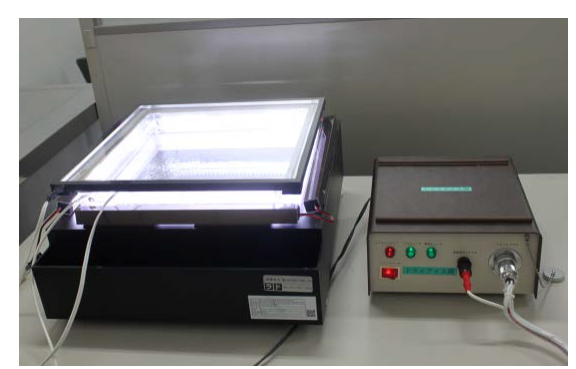

B

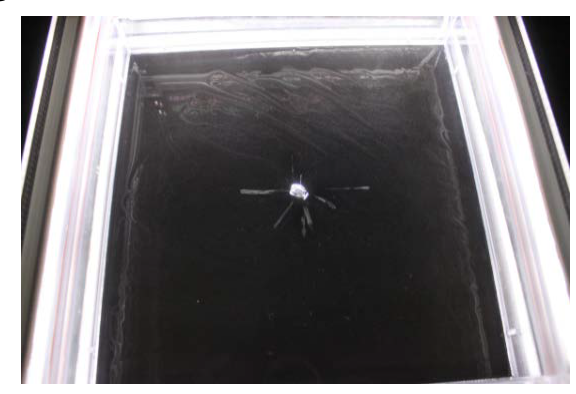

C

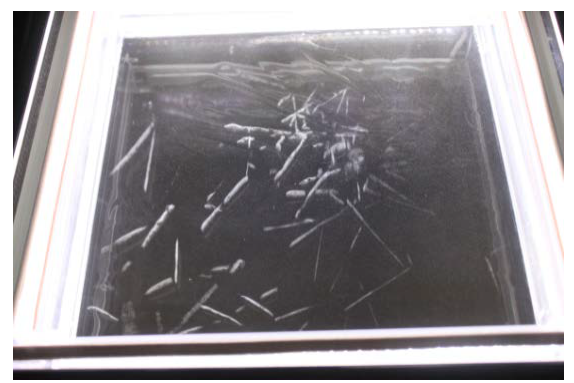

Figure 2: Visible tracks of alpha particles in a cloud chamber. A cloud chamber allows viewers to see the tracks made by charged particles in real time. The chamber contains alcohol vapor. Heat applied to the cover and cooling on the bottom create a supersaturated vapor on the bottom of the chamber. Then, a mist of alcohol forms around the ions produced along the path of the charged particles, which allows visualization of this trait of radiation. (A) The largescale cloud chamber used in the school visits. The cloud chamber is on the left, and the power supply for lighting and heating in the cloud chamber is on the right. The bottom of the cloud chamber is cooled by dry ice. (B) Tracks of alpha particles and their decay can be observed from euxenite, a mineral. (C) Tracks of alpha particles and their decay can be observed from radon.

\section{Questionnaire about the class}

At the end of the course, all 258 students were asked to complete the questionnaire to evaluate the effect of the school visits. Figure 3 shows the responses to the questions. The response rate was $100 \%$. Science or mathematics was the most favorite subject of only $23 \%$ of the students and the least favorite subject of 39\% (Figure 3A and $3 \mathrm{~B})$. Almost half of the students thought that the content of the class was rather difficult to understand, and more than half though that the content was rather easy or appropriate (Figure 3C). Of most interest was the live experiment: half of the students were interested in the live experiment shown on the TV phone (Figure 3D). Slightly more than $42 \%$ of the students answered that the cloud chamber experience was 
interesting (Figure 3D). Before taking this class, more than $50 \%$ of the students had felt somehow scared of radiation (Figure 4A), but after the class, that percentage had decreased to almost $20 \%$ (Figure $4 \mathrm{~B}$ ). Over $65 \%$ of the students answered that knowledge of radiation was useful for their life (Figure 4C).

\section{Discussion}

Radiation cannot be felt, smelled, or tasted, nor does it induce immediate signs or symptoms after exposure. Because there have been few chances to be exposed to radiation at a significant level, opportunities for learning about radiation have been limited.

A

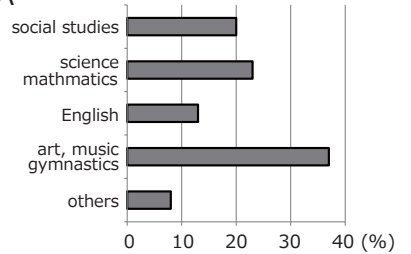

B

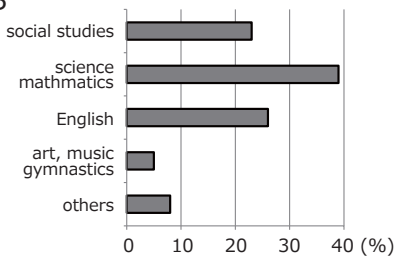

C

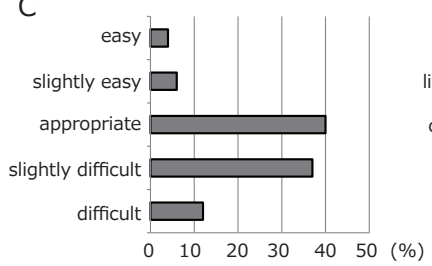

D

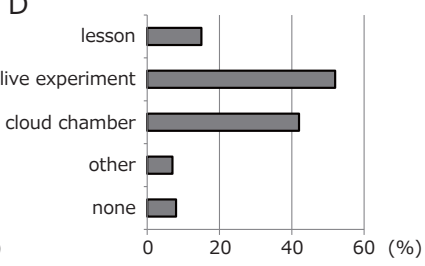

Figure 3: NIRS queried students about their interest in subjects and the contents of the special lesson to evaluate and improve the lesson taught at school visits. The questionnaire was provided to all students who took the class. Graphs show the percentage of students responding to each of the following questions: (A) What is your most favorite subject? (B) What is your least favorite subject? (Social studies includes history, geometry, and economics/politics). (C) How was the special lesson? (D) Which subject was most interesting? (Multiple answers were allowed for this question).

A
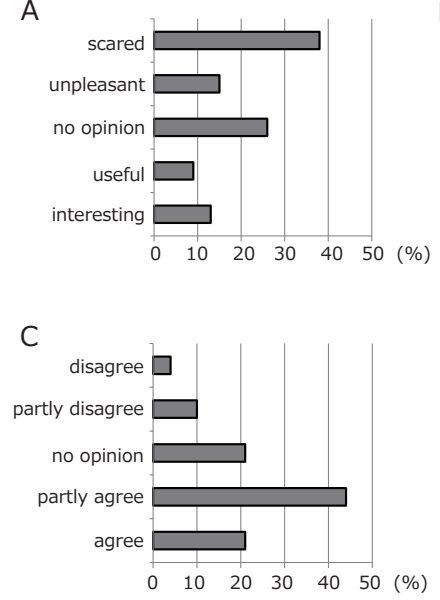

Figure 4: A questionnaire survey was carried out to examine the effects of the special class on the students. NIRS queried the students about their impression of radiation before and after taking the class and about their knowledge of radiation in life. The questionnaire was provided to all students who took the class. Graphs show the percentage of students responding to each of the following questions: (A) Before you took the special lesson, how had you felt about radiation? (B) After you took the special lesson, how do you feel about radiation? $(\mathrm{C})$ Is knowledge about radiation useful for your life?
Therefore, the public did not have adequate knowledge on radiation and its effects. With the Fukushima accident, however, large amounts of radioactive materials were released into the atmosphere, and a lot of information of various quality was spread among the public. Although society started to realize that education on radiation basics should be required in schools, the problem was that there was no human resources or materials/equipment for teaching radiation basics in schools. Furthermore, teachers in schools were too busy. Thus, NIRS started a trial to visit schools teach a class on radiation basics in 2016 .

After the Fukushima accident, NIRS increased its number of regularly scheduled courses, and the number of people who attended these courses reached a plateau. However, NIRS also conducted more on-demand courses especially for teachers and students. NIRS has been involved in the education and training of experts or professionals for 57 years. However, providing these opportunities to teachers and students is a big challenge because providing information in a certain way sometimes can lead to confusion among them, and the NIRS staff has to study communication countermeasures to avoid this risk.

Most of the on-demand training courses were for students who voluntarily participated in and, apparently, were interested in radiation before taking the courses. The remaining courses were for students who had studied science or medicine. However, the NIRS school visit targeted all ninth-grade students in public junior high school, which means almost all of the children at the specific ages in a district, including those who are not good at science nor those who are willing to participate in a special activity to learn science. In fact, at the school visits, less than $23 \%$ of the student stated that they liked science, and $39 \%$ answered that science or mathematics was their least favorite subject. Thus, school visits can promote students in various course and classes to gain knowledge on radiation, leading to mitigation of the misunderstandings about radiation in society.

It appeared that more than half of the students understood the contents of the lesson. However, because almost half of the students also thought that the class was somewhat difficult, further improvement is required, such as by using more instruments and easier explanations, to describe radiation concepts more clearly. Moreover, it might be helpful to use fictional characters and events to attract more classroom attention.

The students were interested in the live experiment by TV phone and the cloud chamber, indicating that obtaining knowledge through visual examples was readily acceptable and that this technique, although well known in society but unfamiliar to the younger age, was a good tool with which to arouse the students' interest. These instruments helped to promote the understanding of radiation by the students. The use of a survey meter was also well accepted by the students (data not shown). These results indicate that the appropriate use of instruments will increase their understanding. After taking the class, the students' feelings about radiation dramatically changed from "scared" to "interesting", indicating that effective education can decrease fear and increase scientific interest. Moreover, $65 \%$ of the students thought that knowledge of radiation was useful for their life.

The Fukushima disaster has caused many people to relocate from Fukushima to other prefectures. Recently, there are still reports of children from Fukushima becoming targets of school bullying in other prefectures [2,3]. In fact, one case of bullying in Yokohama city was 
Citation: Shimizu Y, lida H, Nenoi M, Akashi M (2017) Importance of Supporting School Education on Radiation After the Fukushima Daiichi Nuclear Power Plant Accident. J Health Educ Res Dev 5: 214. doi: 10.4172/2380-5439.1000214

recognized as a grave concern by a third party, the local education board in 2016. It is generally thought that school bullying is caused mainly by stress from the heavy burden at school. However, in this case, one main cause was thought to be harmful rumors or misinformation in society. Children's behavior might reflect anxiety in society. Thus, education is the most powerful tool to improve this situation, to decrease the damage to one's reputation, and to promote restoration of normal life following the accident.

In summary, we learned that it is necessary to support and sustain school education on radiation. NIRS has conducted classes and has distributed a mini-textbook at school visits. We believe that these are helpful for school teachers because these schools do not have devices for radiation detection and the teachers do not have enough knowledge about radiation to teach it. In addition, we are planning a service to lend a survey meter to the schools. This sustainable support will lead to the promotion of recovery from the Fukushima Daiichi NPP accident.

\section{References}

1. Website of the Ministry of Education, Culture, Sports, and Science and Technology (2017) Japan.

2. Wilson T, Funakoshi M (2017) Six years on, Fukushima child evacuees face menace of school bullies. Reuters.

3. University Teacher Harassed Fukushima Student (2017) NHK WORLD.

4. Hachiya M, Akashi M (2016) Lessons learned from the accident at the Fukushima Dai-ichi nuclear power plant - more than basic knowledge: education and its effects improve the preparedness and response to radiation emergency. Radiat Prot Dosimetry 171: 27-31.

5. Shimizu $\mathrm{Y}$, lida $\mathrm{H}$, Nenoi $\mathrm{M}$ (2016) Trends of training courses conducted in Human Resources Development Center of National Institute for Quantum and Radiological Science and Technology after the Fukushima Dai-ichi nuclear power plant accident. Health Physics. 